side-effects than we have recorded, but they did not record the incidence of minor oral side-effects such as sore tongue. The incidence of diarrhoea found in our study is much the same as McCorry and Weaver recorded, although much less than that found by Garrod and Waterworth (195960 ), who reported diarrhoea in 32 out of 141 patients receiving tetracycline hydrochloride.

Despite the conflict of the drug levels in the serum, which were anyhow not conclusive, the clinical trial indicated that lymecycline was an acceptable alternative to tetracycline hydrochloride judged both by therapeutic response and by the incidence of side-effects, but without having any great advantage over the latter drug.

However, there is one criticism of the compound as it is used at present which must be made. There is confusion in the Italian literature, which we have seen only in translation, over the dose of lymecycline employed in earlier studies. This has occurred because the dose has been recorded as weight equivalents to other tetracycline preparations and not to weights of the compound itself. We do not know if this.way of recording the dose is justified, but presumably it arises because, in the preparation of lymecycline, tetracycline base is the starting substance, and the final product is subsequently standardized for activity using tetracycline base or tetracycline hydrochloride as comparative standards. In fact, all lymecycline preparations have less activity than equivalent weights would lead one to expect because of additional moisture and the presence of a small percentage of inactive but non-toxic tetracycline epimers. The presence of such factors may not even be suspected if a subsequent correction back to a tetracycline standard is made, but strictly one should be aware of their presence.

Some Italian papers report the use of doses of lymecycline in tetracycline base equivalents and others in tetracycline hydrochloride equivalents; this is actually a difference of $8.2 \%$, which, when comparative studies are made, could lead to appreciable differences. To underline this confusion, in two communications clearly based on the same data de Carneri et al. (1961) refer to doses given to volunteers as equivalent to $150 \mathrm{mg}$. of tetracycline hydrochloride, and de Carneri (1961) to doses equivalent to $150 \mathrm{mg}$. of tetracycline base. In any further studies on this compound it would seem desirable that the dose employed should be recorded as the weight of the compound itself.

\section{Summary}

Serum levels and urinary excretion of lymecycline (tetracycline-L-methylenelysine; Tetralysal) and tetracycline hydrochloride were compared in volunteers. Lymecycline showed higher serum levels in relation to dose administered and a higher percentage absorption of the dose. In a subsequent clinical trial serum levels from patients showed no statistically significant difference, though levels in the tetracycline hydrochloride group were slightly higher. Therapeutic response was equally satisfactory in both groups and the incidence of side-effects was the same. It is suggested that in future work with lymecycline the dose should be recorded as the weight of the compound itself.

Our thanks are due to Dr. M. E. Solari, of Chelsea College of Science and Technology, for a statistical analysis, and to Fraser Chemicals Ltd. for supply of lymecycline and control tetracycline hydrochloride capsules for use in the clinical trial. In addition, we would like to thank the physicians and surgeons on the staff of the Queen Elizabeth Hospital, Birmingham, for their kindness in allowing us to conduct the clinical trial of this drug on patients under their care.

\section{REFERENCES}

Barber, M., and Garrod, L. P. (1963). Antibiot, and Chemother., p. 230. Bond, J. M., Lightbown, J. W., Barber, M., and Waterworth, P. M. Bond, J., M., Lightbown, J. W.,

de Carneri, I. (1961)." Communications to the 2nd International Symposium of Chemotherapy, Naples, 14-17 September 1961.

- Coppi, G., Lauria, F., and Logemann, W. (1961). Farmaco, Ed. prat., 16, 65.

and Manfredi, N. (1962). Arzneimittel.-Forsch., 12, 1174.

Finland, M., and Garrod, L. P. (1960). Brit. med. Ұ., $2,959$.

Garrod, L. P., and Waterworth, P. M. (1959-60). Antibiot. Ann., p. 440. McCorry, R. L., and Weaver, J. A. (1955). Lancet, 1, 1102.

Purcell, E. M., Wright, S. S., Mou, T. W., and Finland, M. (1954). Prcell, E. M., Wright, S. S., Mou, T.
Proc. Socp. Biol. (N.Y.), 85, 61.

Putnam, L. E., Hendricks, F. D., and Welch, H. (1953-4). Antibiot. Ann., p. 88 .

\title{
Controlled Comparison of Lymecycline with Tetracycline Hydrochloride in Exacerbations of Chronic Bronchitis
}

\author{
A. PINES,* M.D., M.R.C.P.ED. ; K. PLUCINSKI,* M.D. ; J. S. B. GREENFIELD,* M.B., B.S. ; \\ R. C. MITCHELL,* M.A.
}

Brit. med. F., 1964, 2, 1495-1498

The value of the tetracyclines is often diminished by distressing side-effects. Lymecycline (Tetralysal) is a compound formed of a molecule each of tetracycline, the amino-acid L-lysine, and formaldehyde. In contrast to the customarily used tetracyclines, it is claimed to be much more soluble, stable throughout physiological $\mathrm{pHs}$, and almost completely absorbed from the gut (de Carneri et al., 1961). These properties suggest important advantages for lymecycline. The gastro-intestinal disturbances so common and often so distressing with the tetracyclines should be less, and a smaller dose should be required to reach the same blood levels (de Carneri et al., 1961 ; Capraro, 1963).

We describe a double-blind trial which suggests that lymecycline possesses therapeutic advantages.

\section{Pilot Experience \\ Present Investigation}

Our interest in lymecycline was aroused by a number of instances where patients were unable to tolerate tetracycline but then took an equivalent amount of lymecycline without any trouble. During six months 41 patients were intolerant to tetracycline and in only six was there any significant disturbance when lymecycline was given later. Consequently we began a double-blind trial to compare lymecycline with tetracycline hydrochloride in patients with chronic respiratory disease who had purulent exacerbations. Including later experience, outside

* From Ware Park Hospital, Herts. 
the trial, there have been 76 such patients, only 17 of whom were intolerant to lymecycline as well.

\section{Plan of Trial}

Unmarked and identical capsules of tetracycline hydrochloride $250 \mathrm{mg}$. and of lymecycline $200 \mathrm{mg}$. (containing 150 mg. of tetracycline base) were prepared by the firm of Carlo Erba, Milan. Because of better absorption, this quantity of lymecycline is claimed to give the same clinical effect as 250 mg. of tetracycline hydrochloride (de Carneri et al., 1961). The quantities were verified in three different samples by independent microbiological assay. The capsules were issued in bottles labelled $A$ or $B$, the nature of which was kept secret from all the hospital staff conducting the trials. The allocation of treatment $\mathrm{A}$ or $\mathrm{B}$ was by random sampling. The treatment consisted of two capsules of A or B four times daily for the first week, then one capsule four times daily for two more weeks. Because most of our patients had severe infections, it became clear halfway through the trial that this dose was not enough. Eight capsules daily were then given for two full weeks, followed by four capsules daily for a week, and the trial was adjusted in this respect only. The capsules were always administered before meals except for the third daily dose, which for administrative reasons had to be given after supper.

The patients-all of them men-were being treated in the one hospital. Those with carcinoma of the lung or active tuberculosis, or who were so ill that other treatment was indicated, were excluded. One hundred patients were treated, but for reasons described later 10 were discarded and only 90 remained in the study. The great majority ( 82 out of 90 ) had exacerbations of chronic bronchitis; the remainder had bronchiectasis (6) or bronchitis with lobar pneumonia (2). All had purulent sputum at the beginning of treatment. Many had exceptionally severe chronic bronchitis and had often been transferred to this hospital because treatment elsewhere had failed. Patients entered the trial once only. The trial took place from April to December 1953.

The initial features recorded were age ; weight ; the amount, character, and bacteriology of the sputum; fever ; white-cell count; and the general state of the patient as judged by the admitting doctor. Throughout the trial the temperature and the amount and macroscopic purulence of the sputum during each 24 hours were recorded. The sputum was defined as purulent, mucopurulent, or mucoid. We wished to find out which compound gave rise to minor and which to more serious side-effects. The patients were asked weekly about any untoward symptoms they had noticed, even if they had not complained before. If they had complained and were obviously troubled by the side-effects, this was regarded as sufficient reason to change to the alternative compound. The same daily observer, an experienced charge nurse, was used during the trial. Bacteriological investigation was done by standard routine methods and without elaborate research. One specimen was examined at the start of treatment and one at the end.

At the end of the first week the treatment was reviewed together by the two supervising physicians and by the daily observer, who, like the rest of the staff, were ignorant of the nature of the capsules. If it appeared to be succeeding as measured by general clinical impression, and especially if the sputum was becoming mucoid, the treatment was continued with the same compound. If not, then the alternative compound was given in full dosage-that is, eight capsules daily for one, or later in the trial for two, weeks followed by two (or later one) weeks of four capsules daily. Similarly, if side-effects were sufficient to disturb the patient seriously, or to make him demur or reject the treatment, the alternative compound was given in full dosage. At the end of the course the treatments were assessed as successful, as partially successful, or as having failed, both on general clinical grounds and on the recorded data. The macroscopic disappearance or persistence of pus was confirmed in most cases by microscopy.

\section{The Patients}

One hundred treatments were given. Three patients were withdrawn from the trial because they had active tuberculosis, three others were re-treated and the second course was therefore invalidated, and in four the treatments were too late for study. There remained 90 treatments for analysis. In 41 patients lymecycline was given: 27 continued throughout on lymecycline and 20 were changed later to tetracycline hydrochloride. Forty-nine patients were given tetracycline hydrochloride : 24 continued throughout on this drug and 25 changed to lymecycline.

Nearly all the patients were over 50 years of age and were moderately or severely ill. Despite this, fever, raised white-cell count, and radiographic evidence of consolidation were infrequent. Respiratory function tests were found to be impracticable because many patients were too ill to co-operate. Table I shows that both treatment groups were comparable throughout: there were no differences which were statistically

TABLE I.-Comparison of Initial Features of Both Groups

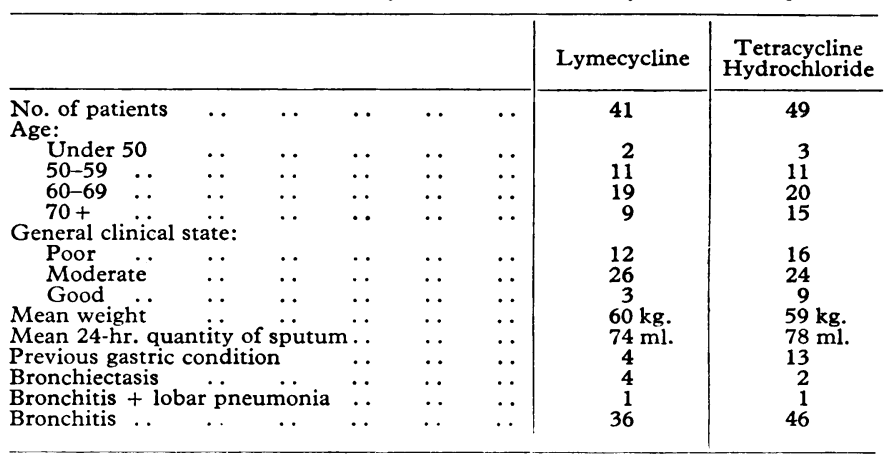

significant before treatment began. The likelihood that there were more previous gastric conditions among the patients treated with tetracycline hydrochloride is only $1: 5$.

In 38 patients potential pathogens were isolated on admission and were distributed equally among the groups. They included Haemophilus influenzae (in 10), Staphylococcus aureus (in 9), Proteus vulgaris (in 8), Streptococcus pneumoniae (in 4), Escherichia coli (in 4), Streptococcus pyogenes (in 2), and Klebsiella pneumoniae (in 1). Probably H. influenzae and Str. pneumoniae were the only significant pathogens and could have been isolated more frequently if more time and special research methods could have been employed than were available in a busy general hospital laboratory (May, 1954). Occasionally E. coli may be a pathogen (Pines et al., 1963). These three organisms often disappeared with successful treatment and persisted when it failed. In a few instances they could still be isolated though the sputum had become mucoid; this is not surprising with tetracycline, which is chiefly bacteriostatic and cannot kill all the bacterial population. Staph. aureus and $P$. vulgaris very often persisted though the sputum had become mucoid; they probably originated from the nasopharynx and not from the bronchi, and were not responsible for the purulence of the sputum. We found that disk sensitivities to tetracycline hydrochloride were unreliable; treatment failed though the organism was sensitive in vitro and succeeded when it was apparently resistant. The unreliability of the crude disk diffusion method is widely recognized (J. R. May, personal communication, 1964). As the antibacterial spectra of tetracycline hydrochloride and lymecycline are identical (de Carneri et al., 1961 ; Whitby and Black, 1964), no separate tests for lymecycline sensitivity were done. 


\section{Results}

The factor which corresponded most closely with the clinical impression of success or failure was the presence of purulent sputum and its change to a persistent mucoid with successful treatment. This is clearly shown in Table II, where for the sake of clarity only complete successes or-failures are considered. Changes in the quantity of sputum were not closely correlated with clinical success or failure. Fever and changes in the white-cell count or in radiographs have not been tabulated, because they occurred too infrequently to be of value in assessment.

TABLE II.-Correlation of Sputum State with Clinical Assessment of Treatment Taking Only Complete Successes or Failures and Excluding 19 Switches of Drugs

\begin{tabular}{|c|c|c|}
\hline \multirow{2}{*}{$\begin{array}{l}\text { Day on which Sputum } \\
\text { became Mucoid }\end{array}$} & \multicolumn{2}{|c|}{ Final Clinical Assessment } \\
\hline & Success & Failure \\
\hline $\begin{array}{l}\text { 2nd } \\
\text { 3rd } \\
4 \text { th } \\
5 \text { th } \\
8 \text { th } \\
10 \text { th }\end{array}$ & $\begin{array}{l}4 \\
6 \\
5 \\
7 \\
4 \\
3\end{array}$ & $\begin{array}{l}= \\
\overline{1} \\
=\end{array}$ \\
\hline $\begin{array}{c}\text { 13th } \\
14 \text { th } \\
\text { 17th } \\
\text { 28th } \\
\text { Never } \\
\text { No answer }\end{array}$ & $\frac{\overline{1}}{\overline{1}}$ & $\frac{1}{1}$ \\
\hline Total & 32 & 33 \\
\hline
\end{tabular}

Taking after the 10th day as the cutting point, only one "failure" was included and one "success" excluded.

Lymecycline was at least as effective as tetracycline hydrochloride. This was so in purely randomized initial treatments leaving out patients whose treatment had to be changed because of intolerance (Table III). Where a regimen had to be changed to the alternative one because of failure or side-effects there was little difference. Lymecycline was successful in 10 out of 25 patients started originally on tetracycline hydrochloride, and tetracycline hydrochloride in 7 out of 20 patients started on lymecycline. Lymecycline gave more complete successes than tetracycline hydrochloride, but the difference is not significant (Table III).

TABLE III.-Final Assessments of Initial Treatments Omitting 19

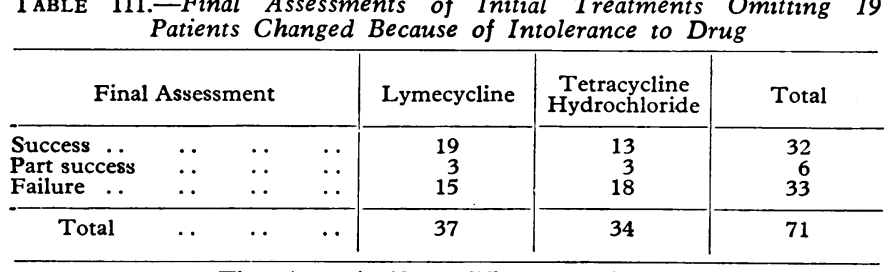
There is no significant difference: $P$ is 0.9 .

When eight capsules a day were given for two weeks rather than one week results tended to be better, but treatments were too few for the improvement to be regarded as significant. Whether patients had chemotherapy or not before entering the trial did not influence the results. In 10 of the patients whose treatment had failed the sputum was examined for eosinophils and for fungi to see if these could account for the persistent purulence: the examinations were all negative.

There were significant differences in the incidence of sideeffects, and lymecycline was better tolerated than tetracycline hydrochloride (Tables IV and V). With lymecycline, sideeffects throughout the trial occurred in 13 out of the 60 patients who were given this drug either initially or later, and were serious enough to require its discontinuance in just over half. With tetracycline hydrochloride side-effects occurred in 23 out of 60 patients and caused discontinuance in nearly threequarters. The effects described were mainly nausea, vomiting, and a burning sensation in the mouth, throat, or abdomen. Depression, sore tongue, and pruritus were common. Profuse watery diarrhoea occurred three times, and only in the patients treated with tetracycline hydrochloride. Minor frequency of the bowels was ignored.

TABLE IV.-Side-effects Throughout the Trial, Including 45 Patients Switched From One Drug to the Other

\begin{tabular}{|c|c|c|c|c|}
\hline \multirow[b]{2}{*}{ Drug } & \multirow{2}{*}{$\begin{array}{l}\text { No. of } \\
\text { Patients } \\
\text { Treated }\end{array}$} & \multicolumn{2}{|c|}{ Side-effects with } & \multirow[b]{2}{*}{ Total } \\
\hline & & $\underset{\text { Treatment }}{\text { Initial }}$ & $\begin{array}{c}\text { Later } \\
\text { Treatment }\end{array}$ & \\
\hline $\begin{array}{l}\text { Lymecycline } . . \\
\text { Tetracycline hydro- } \\
\text { chloride .. }\end{array}$ & $\begin{array}{l}66 \\
69\end{array}$ & $\begin{array}{r}7^{*} \\
20^{*}\end{array}$ & $\begin{array}{l}6 \\
3\end{array}$ & $\begin{array}{l}13^{*} \\
23 *\end{array}$ \\
\hline
\end{tabular}

*Difference significant at the $5 \%$ level of $\chi^{2}$.

TABLE V.-Side-effects and Influence on Therapy

\begin{tabular}{|c|c|c|c|c|c|}
\hline \multirow{2}{*}{\multicolumn{2}{|c|}{$\begin{array}{l}\text { Causing discontinuance } . . \\
\text { Not causing discontinuance } \quad \ldots \\
\text { Uncertain if causing discontinuance }\end{array}$}} & & & \multirow{2}{*}{$\begin{array}{c}\text { Lymecycline } \\
7 \\
6 \\
0\end{array}$} & \multirow{2}{*}{$\begin{array}{c}\begin{array}{c}\text { Tetracycline } \\
\text { Hydrochloride }\end{array} \\
17 \\
4 \\
2\end{array}$} \\
\hline & & $\begin{array}{l}\ldots \\
\cdots\end{array}$ & $\begin{array}{l}\ldots \\
\cdots\end{array}$ & & \\
\hline Total side-effects & .. & . & $\ldots$ & 13 & 23 \\
\hline
\end{tabular}

Fifteen out of the 20 patients who had side-effects with tetracycline hydrochloride had to be changed to lymecycline: nine took an equivalent amount of lymecycline without trouble, but six were intolerant to this drug too. Four out of the seven patients who had trouble with lymecycline were changed to tetracycline hydrochloride: only one tolerated the drug.

\section{Discussion}

In the relative dosage given and in the conditions of this trial, lymecycline was superior to tetracycline hydrochloride in tolerance and equal in clinical effects. Since the active amount of lymecycline given was just over half that of tetracycline hydrochloride (1.2 g. and $2 \mathrm{~g}$. respectively) its better tolerance is not surprising. Nevertheless, as judged by our completely blind assessment, the clinical effect of this relatively smaller dose was at least equal. This gives clinical support to the experimental suggestions that lymecycline is better absorbed from the gut than tetracycline hydrochloride (see below).

The plan of the trial may be criticized because patients and staff could attach likes or dislikes to a definite compound, A or $\mathrm{B}$, though not knowing which of the drugs these really were. A completely blind allocation of unknown treatments by an independent individual would have been better, but this was impracticable because of staff difficulties. Opinions of patients and staff were noted at intervals during the trial and superior or inferior tolerance was attributed equally to treatment $\mathrm{A}$ or $B$, varying from week to week with the latest experience. Some were surprised when the identities of the drugs were revealed at the end of the trial.

We have had to give our patients larger doses of tetracycline and for longer than is sometimes customary because very many had severe and refractory illnesses. Even in cases of mild bronchitis attending as out-patients we often found it necessary to give at least 1.5 or even $2 \mathrm{~g}$. of tetracycline hydrochloride daily for 10 days or more. Nevertheless, in nearly half of our patients in this trial treatment failed. With lower doses of lymecycline and of tetracycline hydrochloride, differences of tolerance might not be so marked, but the rate of failure would have been proportionately higher.

Side-effects occurred in a third of the patients given tetracycline hydrochloride (though only in a fifth of those given lymecycline). This is a higher proportion than perhaps encountered normally. Our patients were usually elderly, had been ill for a long time, and had had long previous periods of hospitalization and chemotherapy, both in this hospital and in other hospitals from which many had been transferred because treatment had failed. Often their nutrition had been 
very bad, not only from illness but also from poor economic and social circumstances. All this, together with the high and prolonged dosage of tetracycline required to overcome their infections, accounts for the high incidence of side-effects. In fact, in published series of bronchitic and bronchiectatic patients, this incidence varies from $8 \%$ when $0.5 \mathrm{~g}$. is given daily (Buchanan et al., 1958) to $60 \%$ with $2 \mathrm{~g}$. daily (Sobel et al., 1962). Garrod and Waterworth (1959-60) noted diarrhoea in $22.7 \%$ out of 141 cases.

Obviously the incidence of side-effects will vary with different factors: the higher the dose and the longer the treatment, the greater the side-effects. Out-patient trials are not comparable: it is well known that many out-patients will not take their drugs properly, particularly if, like tetracycline, they may give rise to unpleasant side-effects. Para-aminosalicylic acid is a well-known example (Simpson, 1956). Further, patients' reactions to the drugs cannot be closely observed, and those who are conducting the trial may vary greatly in their standard of assessment. Probably some of our patients could have been persuaded to continue with the offending compound, but this would have blurred the assessment and would not have allowed the alternative compound to be tried instead. We are convinced that tetracycline hydrochloride gives rise to much minor unpleasantness, though patients often mention this only when asked. Lymecycline, though not always perfectly tolerated, is a much more acceptable compound.

Side-effects are common with the tetracyclines, are proportionate to dose and duration, and quite often interfere with treatment (Barber and Garrod, 1963). Direct irritation of the gut and overgrowth of resistant organisms and of Candida albicans are usually responsible and are largely due to the unabsorbed antibiotic. The side-effects increase with dose because the proportion of tetracycline unabsorbed rises when larger amounts are given. With lymecycline we have shown a significant decrease in side-effects. In particular, profuse watery diarrhoea, which may be dangerous because of staphylococcal superinfection, occurred only in the patients treated with tetracycline hydrochloride. Staphylococcal enteritis is a particular complication of pyrrolidinomethyl tetracycline, which otherwise has properties comparable to lymecycline when given by injection (Lundsgaard-Hansen et al., 1960). Side-effects are said to be reduced when nystatin or vitamins of the B group are added, but the evidence is unconvincing. Compounds such as demethylchlortetracycline and methacycline may be effective in smaller dosage, with fewer side-effects: we are investigating this.

The experimental data suggest that lymecycline is absorbed much better than tetracycline hydrochloride and so can be given in smaller amounts with less disturbance of the gut by unabsorbed residue (Mandelli and Coppi, 1961; Capraro, 1963). The drug is much more soluble than tetracycline hydrochloride and at all physiological pHs (de Carneri et al., 1961), whereas the latter tends to be precipitated in the alkaline duodenum. Though phosphate or citrate is commonly included in the capsule to enhance absorption, a variable and sometimes large proportion still remains unabsorbed (Barber and Garrod, 1963). Tetracycline hydrochloride fluoresces when exposed to light from Wood's lamp. When rats and mice were given tetracycline hydrochloride the fluorescence extended equally throughout the whole intestine, but with lymecycline throughout the small gut only, indicating that it was far better absorbed (Tubaro and Banci, 1963). Full comparative excretion studies do not seem to have been done, however.

In humans, lymecycline yields blood levels that are higher and more quickly reached (de Carneri et al., 1961). In human volunteers Whitby and Black (1964) have shown significantly higher and more rapidly achieved blood levels with a dose of lymecycline equivalent to $162 \mathrm{mg}$. of tetracycline hydrochloride, as compared with $250 \mathrm{mg}$. of tetracycline hydrochloride itself. They also found greater percentage excretion in the urine with lymecycline, implying that this compound was better absorbed from the gut. Estimations of the faecal residue must be inaccurate, because a proportion of absorbed tetracycline is excreted into the gut through the bile. Increasing the oral dose by an amount equivalent to 600 to $1,200 \mathrm{mg}$. of tetracycline hydrochloride raises the blood level by $80 \%$ (de Carneri and Manfredi, 1962). This is proportionately higher than when tetracycline hydrochloride is doubled in dose (Lentze, 1961).

We have found that lymecycline is equal to tetracycline hydrochloride in clinical effect, though a smaller dose was given. This may be due to factors other than better absorption. Effects in the body may be greater than with tetracycline hydrochloride because the drug is stable at the $p \mathrm{H}$ of serum, whereas tetracycline hydrochloride tends to be precipitated; it is less toxic as shown by the estimation of the $\mathrm{LD}_{50}$ in mice, and gives higher protection in mice against Str. pyogenes (de Carneri et al., 1961).

\section{Summary}

A double-blind trial is described in which 90 patients, most of whom were suffering from chronic bronchitis with purulent exacerbations, were treated with lymecycline $1,600 \mathrm{mg}$. (containing $1,200 \mathrm{mg}$. of tetracycline base) or with tetracycline hydrochloride $2 \mathrm{~g}$. daily. In this smaller dose lymecycline was equal to tetracycline hydrochloride in clinical effect and superior in tolerance. This practical superiority may well apply to patients with other illnesses where high doses of the tetracyclines are indicated, though advantages in tolerance may be less marked when a smaller dose is sufficient.

We are grateful to the nursing staff of Ware Park Hospital for their help in this work. We thank the physicians who transferred their patients to this hospital. We are indebted to Fraser Chemicals Limited and Carlo Erba, Milan, for supplies of lymecycline and of tetracycline hydrochloride and for a grant towards expenses. We are grateful to Professor J. W. Crofton, Department of Respiratory Diseases and Tuberculosis, University of Edinburgh, for his criticism of the paper. Mr. I. M. Apor gave us valuable help throughout. Mr. N. L. Allport performed the microbiological assays. We thank Dr. W. D. Linsell and the staff of the Pathological Department, Hertford County Hospital, for the bacteriological estimations.

\section{REFERENCES}

Barber, M., and Garrod, L. P. (1963). Antibiot. and Chemother., p. 132. Buchanan, J., Buchanan, W. W., Melrose, A. G., McGuinness, J. B., and Price, A. U. (1958). Lancet, 2, 719.

Capraro, V. (1963). Second International Symposium on Chemotherapy, Naples, 1961, 1, 177.

de Carneri, I., Coppi, G., Lauria, F., and Logemann, W. (1961) Farmaco, Ed. prat., 16, 65

- and Manfredi, N. (1962). Arzneimittel-Forsch., 12, 1174.

Garrod, L. P., and Waterworth, P. M. (1959-60). Antibiot. Ann., p. 440.

Lentz, R. (1960). Reverin. Proceedings of Symposium on Antibiotics, Prague, p. 232. Quoted by de Carneri and Manfredi, 1962.

Lundsgaard-Hansen, P., Senn, A., Roos, B., and Waller, U. (1960). F. Amer. med. Ass., 173, 1008.

Mandelli, V., and Coppi, G. (1961). Boll. Soc. ital. Biol. sper., 37, 826. May, J. R. (1954). Lancet, 2, 839.

Pines, A., Lydon, T. J., Plucinski, K., and Barkley, H. (1963). Practitioner, 190, 502.

Simpson, J. McD. (1956). Tubercle (Lond.), 37, 333. Sobel, S., Lichter, E. A., Davis, J. C., Dowling, H. F., Lepper, M. H.,
and Jackson, G. G. (1962). Amer. F. med. Sci., 243, 117/341.

Tubaro, E., and Banci, F. (1963). Boll. chim. farm., 102, 674

Whitby, J. L., and Black, H. J. (1964). Brit. med. f., 2, 1491. 